\title{
(- OPEN ACCESS \\ What trial participants need to be told about placebo effects to give informed consent: a survey to establish existing knowledge among patients with back pain
}

\author{
John Hughes, ${ }^{1}$ Maddy Greville-Harris, ${ }^{2}$ Cynthia A Graham, ${ }^{2}$ George Lewith, ${ }^{3}$ \\ Peter White, ${ }^{4}$ Felicity L Bishop ${ }^{2}$
}

${ }^{1}$ Royal London Hospital for Integrated Medicine, London, UK

${ }^{2}$ Department of Psychology, University of Southampton, Southampton, UK

${ }^{3}$ School of Medicine, Southampton University,

Southampton, UK

${ }^{4}$ Department of Health Sciences, University of Southampton, Southampton, UK

\section{Correspondence to}

Dr Felicity L Bishop, Centre for Clinical and Community, Applications of Health Psychology, Faculty of Social Human and Mathematical Sciences, Building 44 Highfield Campus, University of Southampton, Southampton SO17 1BJ, UK;

F.L.Bishop@southampton.ac.uk

Received 26 September 2016 Revised 25 April 2017 Accepted 14 May 2017 Published Online First 9 June 2017

\begin{abstract}
Introduction Patients require an accurate knowledge about placebos and their possible effects to ensure consent for placebo-controlled clinical trials is adequately informed. However, few previous studies have explored patients' baseline (ie, pretrial recruitment) levels of understanding and knowledge about placebos. The present online survey aimed to assess knowledge about placebos among patients with a history of back pain. Design A 15-item questionnaire was constructed to measure knowledge about placebos. Additional questions assessed sociodemographic characteristics, duration and severity of back pain, and previous experience of receiving placebos.

Setting Participants recruited from community settings completed the study online.
\end{abstract}

Results 210 participants completed the questionnaire. $86.7 \%$ had back pain in the past 6 months, $44.3 \%$ currently had back pain. $4.3 \%$ had received a placebo intervention as part of a clinical trial and $68.1 \%$ had previously read or heard information about placebos. Overall knowledge of placebos was high, with participants on average answering 12.07 of 15 questions about placebos correctly (SD=2.35). However, few participants correctly answered questions about the nocebo effect (31.9\% correct) and the impact of the colour of a placebo pill (55.2\% correct).

Conclusions The findings identified key gaps in knowledge about placebos. The lack of understanding of the nocebo effect in particular has implications for the informed consent of trial participants. Research ethics committees and investigators should prioritise amending informed consent procedures to incorporate the fact that participants in the placebo arm might experience adverse side effects.

\section{INTRODUCTION}

Placebos are an essential component of randomised controlled trials (RCTs). They are used to control for bias, contextual and psychological components of treatment and thus isolate the specific effects of the intervention under investigation. Administering placebos to patients can elicit both beneficial and adverse ('nocebo') effects. Many factors are now known to impact on the strength of the placebo response, including factors associated with the healthcare professional administering treatment, the patient receiving treatment and their therapeutic relationship. ${ }^{1-4}$ Characteristics of the intervention itself, such as medication colour, the form and frequency of administration also influence the strength of placebo response. ${ }^{5-8}$ Nocebo effects are typically linked to patient expectations derived from side-effect warnings and can be conditioned from previous adverse events. ${ }^{9}$ Common nocebo effects include nausea, stomach pains, itching, bloating, depression and sleep problems. ${ }^{10}$

It is important that potential trial participants know about placebo and nocebo effects. At minimum an accurate knowledge of the possible benefits and adverse effects of placebos is necessary to ensure consent to take part in an RCT is adequately informed. In addition, people's understanding of, and attitudes towards, placebos may influence their willingness to participate in placebo-controlled RCTs $^{1112}$ and thus could have implications for fair access. However, information leaflets used in RCTs often provide incomplete or inaccurate information about placebos. Bishop et al found that only 1 of 45 participant information leaflets used in major RCTs in the UK mentioned that placebos may elicit beneficial effects and only four mentioned that placebos can elicit adverse effects. ${ }^{13}$

It is necessary to assess people's baseline knowledge of placebos (ie, before participating in any trial recruitment activities) in order to identify common gaps in knowledge and thus specify the placebo characteristics that should be prioritised for inclusion in participant information leaflets. However, little is known about the public's knowledge of placebos and placebo effects. We surveyed people with back pain to examine current levels of placebo knowledge and identify knowledge gaps. To the authors' knowledge this is the first such study. The objective was to inform improvements to informed consent procedures.

\section{METHODS}

\section{Design and measures}

A web-based cross-sectional survey was conducted. Fifteen true-false items assessed knowledge of placebos (for items, see table 1). Items were developed after consulting with experts in placebo research and examining relevant literature. The questionnaire was pretested with 10 lay volunteers and modified based on their feedback. The survey also assessed demographic characteristics; experience of/sources of knowledge about placebos (to permit an initial assessment of the validity of our knowledge questionnaire); and history and severity of back pain and its impact on daily living, using the validated reliable Chronic Pain Grade 
Table 1 Participants' knowledge about placebos

\begin{tabular}{|c|c|c|c|c|}
\hline Item & $\begin{array}{l}\text { Correct } \\
\text { answer }\end{array}$ & Total \% correct (n) & $\begin{array}{l}\text { Read/heard about placebos } \\
(n=143)+\% \text { correct }(n)\end{array}$ & $\begin{array}{l}\text { Not read/heard about placebos } \\
(n=64) \dagger \% \text { correct }(n)\end{array}$ \\
\hline A pill with aspirin in it is called a 'placebo' pill & False & $98.1 \%(206)$ & $98.6 \%(141)$ & $96.9 \%(62)$ \\
\hline The placebo effect can work because of people's expectations & True & $95.2 \%(200)$ & $99.3 \%(142)$ & $85.9 \%(55)^{* *}$ \\
\hline $\begin{array}{l}\text { Placebo treatments are only effective for people who are not very } \\
\text { intelligent }\end{array}$ & False & $96.7 \%(203)$ & $97.9 \%(140)$ & $93.8 \%(60)$ \\
\hline Placebo treatments can help to treat pain conditions & True & $79.5 \%(167)$ & $82.5 \%$ (118) & $71.9 \%(46)$ \\
\hline Placebo treatments do not help to relieve any medical symptoms & False & $72.9 \%(153)$ & $76.2 \%(109)$ & $65.6 \%(42)$ \\
\hline $\begin{array}{l}\text { Placebo pain treatments only relieve imaginary pain (ie, pain that } \\
\text { was not real in the first place) }\end{array}$ & False & $85.2 \%(179)$ & $89.5 \%(128)$ & $75.0 \%(48)^{* *}$ \\
\hline A pill with no medicine in it is called a 'placebo' pill & True & $91.9 \%(193)$ & $97.9 \%(140)$ & $78.1 \%(50)^{* *}$ \\
\hline The placebo effect can work because of conditioning & True & $74.3 \%(156)$ & $74.8 \%(107)$ & $73.4 \%(47)$ \\
\hline $\begin{array}{l}\text { Real changes in the brain can occur when you receive a placebo (such } \\
\text { as the release of chemicals called opioids) }\end{array}$ & True & $83.8 \%(176)$ & $88.1 \%(126)$ & $73.4 \%(47)^{*}$ \\
\hline $\begin{array}{l}\text { Placebo effects are imaginary and have no real physical effects on } \\
\text { our body }\end{array}$ & False & $81.0 \%(170)$ & $83.2 \%(119)$ & $76.6 \%(49)$ \\
\hline Placebo effects only occur in experiments and research trials & False & $86.2 \%(181)$ & $90.2 \%(129)$ & $76.6 \%(49)^{* *}$ \\
\hline A placebo pill can have side effects & True & $31.9 \%(67)$ & $34.3 \%(49)$ & $28.1 \%(18)$ \\
\hline $\begin{array}{l}\text { The placebo effect can help us to get better during normal medical } \\
\text { treatments }\end{array}$ & True & $79.5 \%(167)$ & $83.9 \%(120)$ & $68.8 \%(44)^{*}$ \\
\hline The colour of a placebo pill can change how effective it is & True & $55.2 \%(116)$ & $60.1 \%(86)$ & $43.8 \%(28)^{*}$ \\
\hline $\begin{array}{l}\text { Placebo treatments are only effective for people who lie about their } \\
\text { symptoms }\end{array}$ & False & $96.7 \%(203)$ & $99.3 \%(142)$ & $90.6 \%(58)^{* *}$ \\
\hline
\end{tabular}

${ }^{*} \mathrm{p}<0.05,{ }^{* *} \mathrm{p}<0.01$, significant $\chi^{2}$.

†Three participants did not specify whether they had previously read or heard about placebos.

Questionnaire. ${ }^{14}$ Participants also completed a 15 -item acupuncture questionnaire (reported separately ${ }^{15}$ ).

\section{Participants}

We surveyed adults with a history of back pain, as back pain is prevalent ${ }^{16}$ and placebos have demonstrated pronounced effects in chronic pain conditions. ${ }^{17}$

\section{Procedure}

Ethical approval was given by the University of Southampton Psychology Ethics Committee.

Fifteen UK universities invited staff and students to participate via email. The study was also advertised on social media sites pertaining to back pain and to local businesses. Adults who had 'had back pain' were invited to take part in a 'short (10 min) online quiz' about alternative treatments for back pain. On clicking a link participants reached an information page presenting study details and a tick-box to indicate consent. Participants then completed the survey.

Data were imported into SPSS V.22 and summarised using descriptive statistics. Analysis of variance, $t$-test, $\chi^{2}$ test and Spearman's correlation test assessed whether knowledge of placebos was related to previous experience of receiving placebos, having read or heard about placebos, gender, age, ethnicity, highest qualification and back pain characteristics.

\section{RESULTS}

\section{Participant characteristics}

Two hundred and twenty-six people participated between July and October 2014. Data were excluded from 16 individuals who failed to complete any placebo knowledge items, leaving 210 participants. One hundred and thirty-six participants were female $(67.7 \%)$ and 65 were male $(32.3 \%)$, aged $18-74$ years
$(\mathrm{M}=35, \mathrm{SD}=14.05)$ (9 skipped these items). All participants reported back pain: $100 \%$ ever had back pain, $86.7 \%(n=182)$ in the past 6 months and $44.3 \%(n=93)$ currently. Of those reporting current back pain, average pain intensity was mild $(\mathrm{M}=3.4, \mathrm{SD}=2.16)$ (see table 2 for additional characteristics).

\section{Experiences of placebos}

Only nine participants $(4.3 \%)$ had previously received a placebo as part of an RCT, but $68.1 \%(n=143)$ reported having previously read or heard about placebos, via friends and family, school/university, general knowledge, books, media and/or the internet.

\section{Knowledge}

Participants answered between 4 and 15 knowledge items correctly $(M=12.07 ; S D=2.35)$ (see table 1$)$. Key gaps in placebo knowledge were identified; $31.9 \%$ knew that a placebo pill can have side effects and 55.2\% knew that the colour of a placebo pill can change how effective it is.

The nine participants who had previously received placebo treatment as part of an RCT $(\mathrm{M}=12.22, \mathrm{SD}=1.64)$ had similar knowledge scores to the 201 who had not $(M=12.06, S D=2.39)$ $(p=0.841)$. However, the 143 participants who reported previously reading or hearing about placebos had significantly higher scores $(\mathrm{M}=12.55, \mathrm{SD}=2.15)$ than the 67 who indicated they had not read or heard about placebos $(\mathrm{M}=10.97, \mathrm{SD}=2.49)$ $(\mathrm{t}=4.663, \mathrm{df}=205, \mathrm{p}<0.001)$.

There were just two differences in knowledge by sociodemographic and clinical characteristics. Participants who identified as white British had higher placebo knowledge scores than other ethnicities combined $(\mathrm{M}=12.47 \quad(\mathrm{SD}=2.18)$ and $\mathrm{M}=11.33$ $(\mathrm{SD}=2.50)$, respectively; $\mathrm{t}=3.422, \mathrm{df}=208, \mathrm{p}=0.001)$. Participants who reported less intense pain during the previous 
Table 2 Participant characteristics

\begin{tabular}{|c|c|c|}
\hline & Number (n) & Per cent $(\%)$ \\
\hline \multicolumn{3}{|l|}{ Gender* } \\
\hline Female & 136 & 67.7 \\
\hline Male & 65 & 32.3 \\
\hline \multicolumn{3}{|l|}{ Ethnic origin } \\
\hline White British & 137 & 65.2 \\
\hline Other White background & 39 & 18.6 \\
\hline Asian or Asian British & 9 & 4.3 \\
\hline Chinese & 7 & 3.3 \\
\hline Other & 16 & 7.7 \\
\hline Preferred not to state ethnicity & 2 & 1.0 \\
\hline \multicolumn{3}{|l|}{ Occupation } \\
\hline Student & 66 & 31.4 \\
\hline Administrator/secretary & 27 & 12.9 \\
\hline Academic & 25 & 11.9 \\
\hline Postgraduate student & 21 & 10.0 \\
\hline Researcher & 19 & 9.0 \\
\hline Teaching & 12 & 5.7 \\
\hline Healthcare professional & 8 & 3.8 \\
\hline Currently not working/retired & 7 & 3.3 \\
\hline Technician/programmer & 7 & 3.3 \\
\hline Care work & 4 & 1.9 \\
\hline Engineering & 2 & 1.0 \\
\hline Other & 12 & 5.7 \\
\hline \multicolumn{3}{|l|}{ Highest level of education } \\
\hline Secondary school & 10 & 4.8 \\
\hline Some college & 31 & 14.8 \\
\hline Bachelor's degree & 50 & 23.8 \\
\hline Master's degree & 58 & 27.6 \\
\hline Doctoral degree & 44 & 21.0 \\
\hline Other & 17 & 8.1 \\
\hline Pain in past 6 months $t$ & Mean & SD \\
\hline Intensity & 4.23 & 1.96 \\
\hline Interference in daily activities & 3.83 & 2.57 \\
\hline Interference in recreational activities & 3.08 & 2.70 \\
\hline Interference in work activities & 2.93 & 2.61 \\
\hline
\end{tabular}

${ }^{*}$ Nine participants did not specify their gender.

tItems answered on a $0-10$ scale, where 10 indicates highest levels of pain intensity/interference.

6 months had higher placebo knowledge scores than those who reported more intense pain $\left(r_{s}=-0.210 ; p<0.01\right)$.

\section{DISCUSSION}

Placebos are an important component of RCTs used to elucidate the specific effects of an intervention under investigation. For informed consent to be valid, trial participants need an accurate knowledge of placebos; this should minimally include an understanding that placebos can have both beneficial and adverse effects. ${ }^{18}$ Our community-based survey of people with back pain found relatively high knowledge overall but only a small minority of participants knew that placebos could have adverse, that is, nocebo, effects. Evidence from meta-analysis suggests as many as $52 \%$ of RCT participants receiving a placebo may experience nocebo effects. ${ }^{19}$ However, just $31.9 \%$ of our participants knew that a placebo can have side effects. Earlier studies elsewhere reported similar findings: $4.8 \%$ of general practitioner patients in New Zealand agreed that placebos can cause bad side effects ${ }^{20}$ and $7.7 \%$ of patients recruited from a rheumatology clinic in France believed placebos can induce adverse effects. ${ }^{21}$ Our study updates and extends this work, suggesting that the UK patients would also benefit from receiving information about nocebo effects before taking part in a placebo-controlled RCT.

A lack of placebo knowledge among potential trial participants has implications for the ethical principle of autonomy, and consequently participants' ability to provide full informed consent. Respect for autonomy requires potential participants to have sufficient information to enable them to make an informed decision regarding participation. In particular, the Declaration of Helsink ${ }^{18}$ requires volunteers to be informed about the potential benefits and harms of participation. The knowledge gaps identified within the present study, combined with the limited descriptions of placebos in participant information sheets found previously, ${ }^{13}$ suggest that in many cases participants do not have an adequate understanding of the potential benefits and harms of placebos before consenting to placebo-controlled RCTs. This would appear to violate the principle of autonomy, and may question the ethical validity of consent. ${ }^{22}$

There is increasing awareness that ethical practices, such as the content of participant information sheets, should be grounded in empirical data. ${ }^{2324}$ However, there remains a dearth of published research to inform investigators and research ethics committees. This study was strengthened by using evidence-based items to assess placebo knowledge objectively. The fact that participants who had previously read or heard about placebos scored higher than other participants provides initial evidence for the construct validity of the knowledge questionnaire.

Selection bias is a limitation; participants were more highly educated than the general UK population (almost 50\% possessed a postgraduate qualification). This may have driven the high placebo knowledge scores and a more representative sample might have exhibited less knowledge; indeed, even lower levels of knowledge about nocebo effects have been reported by others. ${ }^{2021}$ However, educational attainment was not related to placebo knowledge in this sample.

Research ethics committees and investigators should prioritise amending informed consent documentation and procedures to explain that participants in the placebo arm might experience beneficial and adverse effects. Our findings suggest that while volunteers may have some existing knowledge that placebos can elicit beneficial effects, they are far less likely to appreciate their potential to elicit adverse effects. Adding information about nocebo effects to participant information sheets and associated discussions might therefore increase participants' capacity to provide ethically valid informed consent. Future research could evaluate placebo knowledge gaps in other patient groups and develop resources and guidelines to improve the provision of patient information about placebo and nocebo effects. In the meantime, we recommend that research ethics committees apply greater scrutiny to the description of placebos in participant information sheets.

Acknowledgements The authors would like to thank participants for completing the online questionnaire.

Contributors $\mathrm{MGH}$ and $\mathrm{FB}$ conceived and designed the work, with input from CG, GL and PW. MGH collected the data. JGH analysed the data and drafted the manuscript. All authors contributed to data interpretation, revised the work for important intellectual content, approved the version to be published and are accountable for the work.

Funding The study was funded by a grant from Arthritis Research UK (grant reference 20113). 
Competing interests None declared.

\section{Patient consent Obtained.}

Ethics approval Psychology Ethics Committee, University of Southampton, UK.

Provenance and peer review Not commissioned; externally peer reviewed.

Data sharing statement The data reported in this paper may be requested from the corresponding author.

Open Access This is an Open Access article distributed in accordance with the terms of the Creative Commons Attribution (CC BY 4.0) license, which permits others to distribute, remix, adapt and build upon this work, for commercial use, provided the original work is properly cited. See: http://creativecommons.org/licenses/by/4.0/

(C) Article author(s) (or their employer(s) unless otherwise stated in the text of the article) 2017. All rights reserved. No commercial use is permitted unless otherwise expressly granted.

\section{REFERENCES}

1 Smith EB. Effect of investigator bias on clinical trials. Arch Dermato/ 1989;125:216-8.

2 Meaning MDE. Medicine and the placebo effect. Cambridge University Press 2002.

3 Di Blasi Z, Harkness E, Ernst E, et al. Influence of context effects on health outcomes: a systematic review. Lancet 2001;357:757-62.

4 Crow R, Gage H, Hampson S, et al. The role of expectancies in the placebo effect and their use in the delivery of health care: a systematic review. Health Technol Assess 1999:3:3:3.

5 de Craen AJ, Roos PJ, de Vries AL, et al. Effect of colour of drugs: systematic review of perceived effect of drugs and of their effectiveness. BMJ 1996;313:1624-6.

6 Branthwaite A, Cooper P. Analgesic effects of branding in treatment of headaches. $\mathrm{Br}$ Med J 1981;282:1576-8.

7 de Craen AJ, Moerman DE, Heisterkamp SH, et al. Placebo effect in the treatment of duodenal ulcer. Br J Clin Pharmacol 1999;48:853-60.

8 Kaptchuk TJ, Goldman P, Stone DA, et al. Do medical devices have enhanced placebo effects? J Clin Epidemiol 2000;53:786-92.
9 Sanderson C, Hardy J, Spruyt O, et al. Placebo and nocebo effects in randomized controlled trials: the implications for research and practice. J Pain Symptom Manage 2013;46:722-30.

10 Häuser W, Hansen E, Enck P. Nocebo phenomena in medicine: their relevance in everyday clinical practice. Dtsch Arzteb/ Int 2012;109:459-65.

11 Hummer M, Holzmeister R, Kemmler G, et al. Attitudes of patients with schizophrenia toward placebo-controlled clinical trials. J Clin Psychiatry 2003;64:277-81.

12 Welton AJ, Vickers MR, Cooper JA, et al. Is recruitment more difficult with a placebo arm in randomised controlled trials? A quasirandomised, interview based study. BMJ 1999;318:1114-7.

13 Bishop FL, Adams AE, Kaptchuk TJ, et al. Informed consent and placebo effects: a content analysis of information leaflets to identify what clinical trial participants are told about placebos. PLoS One 2012;7:e39661.

14 Von Korff M, Ormel J, Keefe FJ, et al. Grading the severity of chronic pain. Pain 1992; 50:133-49.

15 Greville-Harris M, Hughes J, Lewith G, et al. Assessing knowledge about acupuncture: a survey of people with back pain in the UK. Complement Ther Med 2016;29:164-8.

16 Hoy D, Brooks P, Blyth F, et al. The Epidemiology of low back pain. Best Pract Res Clin Rheumatol 2010;24:769-81.

17 Finniss DG, Kaptchuk TJ, Miller F, et al. Biological, clinical, and ethical advances of placebo effects. Lancet 2010;375:686-95.

18 World Medical Association declaration of Helsinki. Ethical principles for medical research involving human subjects. JAMA 2013;310:2191-4.

19 Papadopoulos D, Mitsikostas DD. A meta-analytic approach to estimating nocebo effects in neuropathic pain trials. J Neurol 2012;259:436-47.

20 Chen GF, Johnson MH. Patients' attitudes to the use of placebos: results from a New Zealand survey. N Z Med J 2009;122:35-46.

21 Berthelot JM, Maugars Y, Abgrall M, et al. Interindividual variations in beliefs about the placebo effect: a study in 300 rheumatology inpatients and 100 nurses. Joint Bone Spine 2001;68:65-70.

22 Blease CR, Bishop FL, Kaptchuk TJ. Informed consent and clinical trials: where is the placebo effect? BMJ 2017;356:j463.

23 Musschenga AW. Empirical ethics, context-sensitivity, and contextualism. J Med Philos 2005:30:467-90.

24 Salloch S, Wäscher S, Vollmann J, et al. The normative background of empirical-ethical research: first steps towards a transparent and reasoned approach in the selection of an ethical theory. BMC Med Ethics 2015;16:20. 